\title{
Evaluation of Natural Degradation of Persistent Organic Chemicals in Acid Sulfate Soils Distributed in a Coastal Area
}

\author{
Junko Hara, Yasuhide Sakamoto, and Yoshishige Kawabe
}

\begin{abstract}
Coastal acid sulfate soils are naturally generated sediments, mainly containing iron sulfides. This study investigated the natural distribution of acid sulfate soils at the mouth of a river, and their remediation ability of persistent organic chemicals. These soils were distributed on a small scale in southern Japan; Iriomote Island was used as the study site. Coastal acid sulfate soils were found to be restricted to the surface in the downstream portions but distribution depth increased upstream. The shallow, surficial portion of acid sulfate soils in upstream areas had already oxidized and leached sulfuric acid. The degradation ability of sampled acid sulfate soils for dieldrin was confirmed in laboratory experiments and the degradation ability was found to increase with iron sulfide content. These reactions were controlled by the chemical reactivity of iron sulfides in natural systems but independent of microbial activity.
\end{abstract}

Index Terms-Natural attenuation, persistent organic chemicals, acid sulfate soils, oxidative degradation.

\section{INTRODUCTION}

Persistent organic compounds are resistant to decomposition, and spread easily through air and accumulate in living organisms. They diffuse extensively throughout the environment and are concentrated in highly advanced predators. These toxic materials are regulated globally, but their proliferations as well as their diffusion and degradation processes have not been studied to date. Our previous research made clear that natural iron sulfide was able to decompose chlorinated organic materials by oxidative reaction processes [1], [2]. Metal sulfides have vastly differing electrical and magnetic properties. Among them, iron sulfides are the abundant, and their surface reactivity has been reported in detail [3]-[5]. The iron sulfide/water and iron sulfide/oxygen reactions occurring at the surface produce active radicals [5]. Although the active radicals generated from the pyrite/water and pyrite/oxygen reactions differ under redox conditions, they nonetheless cause the oxidation and polymerization of chlorinated organic chemicals by several radicals arising from the pyrite/water, pyrite/oxygen interface reaction. This mechanism degrades the toxic chlorinated organic materials.

Iron sulfides occur in several areas, including metal mines, hydrothermal alteration areas, muddy sediments, and lakes

Manuscript received June 3, 2015; revised August 5, 2015.

The authors are with the Research Institute for Geo-Resources and Environment, National Institute of Advanced Industrial Science and Technology, Tsukuba, Japan (e-mail: j.hara@ aist.go.jp, sakamoto-yasuhide@aist.go.jp, y-kawabe@ aist.go.jp). with reducing conditions. Pyrite especially occurs in acid sulfate soils found in coastal areas or in reclaimed land in tropical and subtropical zones. These soils are extensively distributed in South and Southeast Asia, West Africa, and the Northeastern coast of South Africa [6]. The oxidation of sulfide-bearing soils engenders serious environmental problems by causing acidification of the soil. This is because iron sulfides are stable under anaerobic conditions, but when exposed to air, they undergo sulfuric acid leaching. However, the acid sulfate soils have the potential to be naturally attenuate toxic chlorinated organic compounds, if kept under anaerobic conditions.

This study uses two factors to highlight the ability of acid sulfate soils to cause natural degradation of persistent organic chemicals. The first factor is the location of the soil, i.e. whether it is found inland, in a region of brackish-water or in a marine area, because sediment condition influences the redox reaction in iron sulfides. The other factor is the effect of microbiology. We must be clear whether microorganisms or naturally occurring chemical reactions cause this degradation process.

\section{RESEARCH AREA}

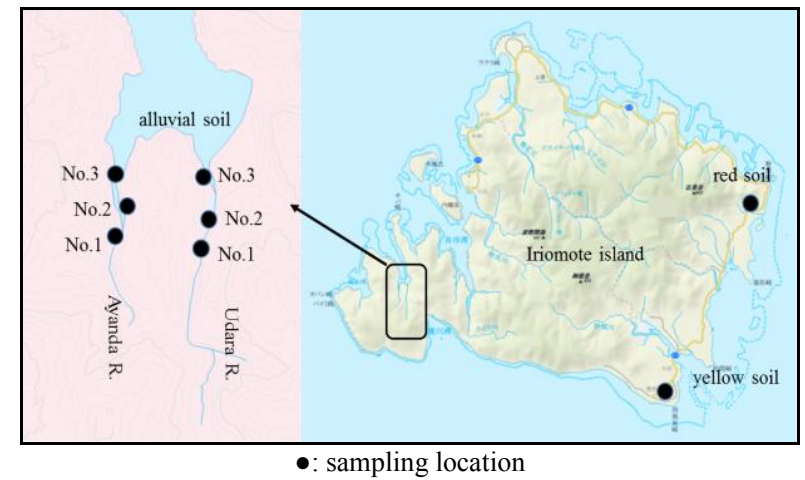

Fig. 1. Map of the sampling location.

Acid sulfate soils distributed in coastal areas are found in coastal mangrove forests. Mangroves can adapt to acidic environments and play an important role in the iron sulfide precipitation during marine regression events. Mangrove forests are to be found in the Kagoshima and Okinawa prefectures in southern Japan. We collected the target soils from Iriomote Island, Okinawa, where there is little artificial modification of the coastal region and it is possible to collect soil samples in genetic environments. Natural mangrobe forests are widely distributed in main river mouths in this island. Red, yellow and alluvial soils were collected in 
Iriomote Island (Fig. 1). The red and yellow soils, which are generally characterized by acid-heavy clay content, were obtained from the eastern portion. This soil type occurs extensively on Iriomote Island. The alluvial soils were obtained at low tide from the mouths of the Ayanda and Udara rivers, where there is abundant mangrove forest.

Iriomote Island in the Okinawa prefecture, is located in a subtropical zone in Japan. Samples were collected from the eastern inland area and western mouths of the Ayanda and Udara rivers.

\section{METHODS}

\section{A. Core Sampling and Evaluation Factor on Soil Character}

The soil samples were collected using a core sampler, and 30 to $50 \mathrm{~cm}$ long cores were obtained at each point. These were degassed and stored at $4{ }^{\circ} \mathrm{C}$ with a deoxidizer. The core samples were freeze-dried in the laboratory and cut at $2 \mathrm{~cm}$ intervals. The cut samples were divided into 2 fractions after sieving to a grain size of $2 \mathrm{~mm}$ and removing the plant fraction. One fraction was used to evaluate the soil characteristics and the other for the degradation ability test.

To determine whether collected soils were acid sulfate soils or not, $\mathrm{pH}\left(\mathrm{H}_{2} \mathrm{O}\right), \quad \mathrm{pH}\left(\mathrm{H}_{2} \mathrm{O}_{2}\right), \quad \mathrm{SO}_{4}\left(\mathrm{H}_{2} \mathrm{O}\right), \quad \mathrm{SO}_{4}\left(\mathrm{H}_{2} \mathrm{O}_{2}\right)$, $\mathrm{SO}_{4}$ (soluble in aqua regia), $\mathrm{SO}_{4}$ (possibility of oxidation), $\mathrm{SO}_{4}$ (facility of oxidation) were analyzed. The $\mathrm{pH}$ and $\mathrm{SO}_{4}$ analysis was conducted as follows: $\mathrm{pH}\left(\mathrm{H}_{2} \mathrm{O}\right)$ was measured using the ratio soil: water $=1: 2.5$ suspended mixture, $\mathrm{pH}\left(\mathrm{H}_{2} \mathrm{O}_{2}\right)$ was measured using the ratio soil : $\mathrm{pH} 6 \mathrm{H}_{2} \mathrm{O}_{2}(30 \%)$ $=1: 10$ suspended mixture by dissolving the volatile fraction, $\mathrm{SO}_{4}\left(\mathrm{H}_{2} \mathrm{O}\right)$ was measured the $\mathrm{SO}_{4}$ concentration after shaking for 1 hour with the ratio soil : water $=1: 5$ followed by filtration. $\mathrm{SO}_{4}$ (soluble in aqua regia) was measured after shaking for 2 hours using the ratio soil: inverse aqua regia $=1$ : 10 at $60-100{ }^{\circ} \mathrm{C}$ followed by filtration, $\mathrm{SO}_{4}$ (possibility of oxidation) was calculated using $\mathrm{SO}_{4}$ (soluble in aqua regia) $\mathrm{SO}_{4}\left(\mathrm{H}_{2} \mathrm{O}\right), \mathrm{SO}_{4}$ (facility of oxidation) was calculated using $\mathrm{SO}_{4}\left(\mathrm{H}_{2} \mathrm{O}_{2}\right) \quad-\quad \mathrm{SO}_{4}\left(\mathrm{H}_{2} \mathrm{O}\right)$. Detailed decision-making methodology was based on Sasaki N. 1978 [7].

In addition, the CHNS contents and inorganic bulk chemical compositions were respectively measured using an organic chemical analyzer (Flash 2000, Thermo) and X-ray fluorescence (EDX-720, Shimadzu Co. Ltd.). The mineral species in soils were also identified by using a powder X-ray diffractometer (XRD) (MinFlex2, Rigaku).

\section{B. Degradation Experiments}

The evaluation of degradation ability was conducted using $100 \mathrm{ml}$ umber vials, soil samples (both sterile and non-sterile), ultra-pure water, and dieldrin as the persistent organic chemical. The sterile soils were prepared by destroying bacteria using an autoclave. Then $10 \mathrm{mg}$ of sterile or non-sterile soil and $10 \mathrm{ml}$ ultra-pure water were put into vials and the air inside was replaced by gaseous $\mathrm{N}_{2}$. Then, $10 \mu \mathrm{mol}$ gaseous $\mathrm{O}_{2}$ and 5 ppm dieldrin were injected into each vial after they were sealed. Every vial was shaken for 30 days at $200 \mathrm{rpm}$, at $25{ }^{\circ} \mathrm{C}$. After a predetermined time, $1.5 \mathrm{ml}$ of reaction water was collected before opening the vials to evaluate the reaction products and chloride ions dissolved in the reaction water, and infused into the surrogate chemical. The dieldrin, surrogate material, and water insoluble reaction intermediates were extracted by hexane/acetone after the surrogate diffused in the soil, and was dehydrated using anhydrous sodium sulfate. Finally, extracted solvents were concentrated to $1 \mathrm{ml}$ and analyzed by GC-MS (GCMS-QP2010 + DI-2010, Shimadzu Co. Ltd).

GC-MS analysis to measure the dieldrin and other organic compounds was carried out with a Rtx-5MS capillary column $(60 \mathrm{~m} \times 0.25 \mathrm{~mm}$ I.D. $\times 0.25 \mu \mathrm{m}$ film thickness, Shimadzu Co. Ltd.). The carrier gas for the GC-MS analysis was ultra-pure helium. The GC conditions had an injection temperature of $150{ }^{\circ} \mathrm{C}$, and the column oven temperature program consisted of $45{ }^{\circ} \mathrm{C}$ (hold $10 \mathrm{~min}$ ) $-12{ }^{\circ} \mathrm{C} \min ^{-1}$ $190{ }^{\circ} \mathrm{C}$ (hold $2 \mathrm{~min}$ ) $-6{ }^{\circ} \mathrm{C} \min ^{-1}-220{ }^{\circ} \mathrm{C}-2{ }^{\circ} \mathrm{C} \min ^{-1}-$ $280{ }^{\circ} \mathrm{C}$ (hold $1 \mathrm{~min}$ ). The temperature of the interface between the $\mathrm{GC}$ and the $\mathrm{MS}$ detector was $250{ }^{\circ} \mathrm{C}$.

\section{RESUlTS AND DISCUSSIONS}

\section{A. The Chemical Character of Red Soil and Yellow Soils}

(a)

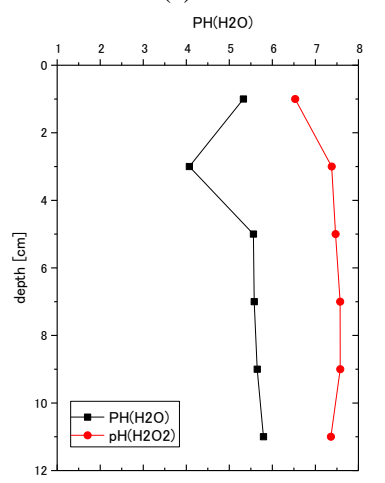

(b)

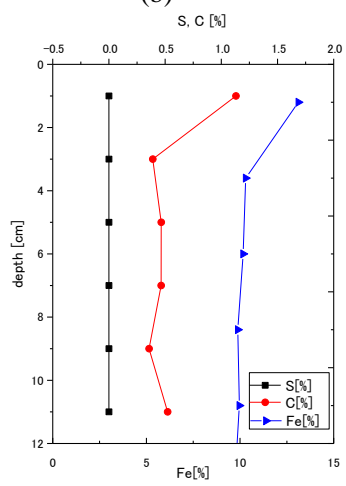

Fig. 2. Depth profiles of chemical character on red soils. (a) $\mathrm{pH}\left(\mathrm{H}_{2} \mathrm{O}\right)$ and $\mathrm{pH}\left(\mathrm{H}_{2} \mathrm{O}_{2}\right)$, (b) $\mathrm{S}, \mathrm{C}, \mathrm{Fe}[\%]$. (a)

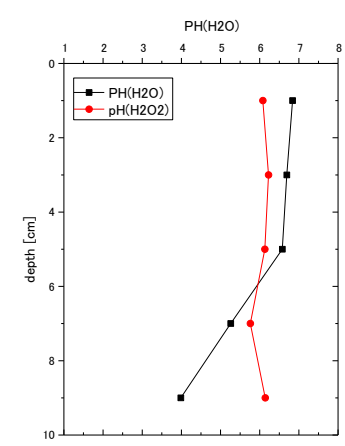

(b)

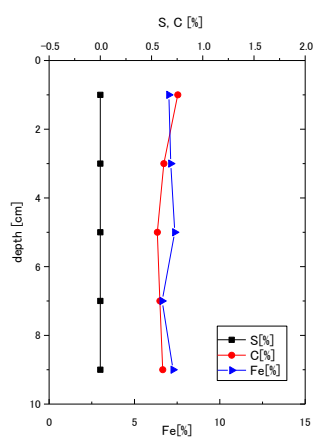

Fig. 3. Depth profiles of chemical character on red soils. (a) $\mathrm{pH}\left(\mathrm{H}_{2} \mathrm{O}\right)$ and $\mathrm{pH}\left(\mathrm{H}_{2} \mathrm{O}_{2}\right)$, (b) $\mathrm{S}, \mathrm{C}, \mathrm{Fe}[\%]$.

Red and yellow soils collected from natural environments exhibited neutral to acid $\mathrm{pH}\left(\mathrm{H}_{2} \mathrm{O}\right)$, but $\mathrm{pH}\left(\mathrm{H}_{2} \mathrm{O}_{2}\right)$ was neutral at all depths and no sulfides or sulfates were detected (Fig. 2, Fig. 3). Iron sulfide minerals were not observed in the XRD analysis. Based on these results, these soils cannot be categorized as acid sulfate soils. They are widely distributed on Iriomote Island. Iron sulfide and the other sulfide minerals 
were not observed, but X-ray fluorescence revealed the contents of iron, manganese, and aluminum to be superior to alluvial soils. However, most of the iron and manganese was already oxidized to ferric or manganese oxide and assumed to be poor at reaction activity on the degradation of chlorinated organic chemicals.

\section{B. The Chemical Character of Alluvial Soils in the Depth Direction}

(a) Udara1

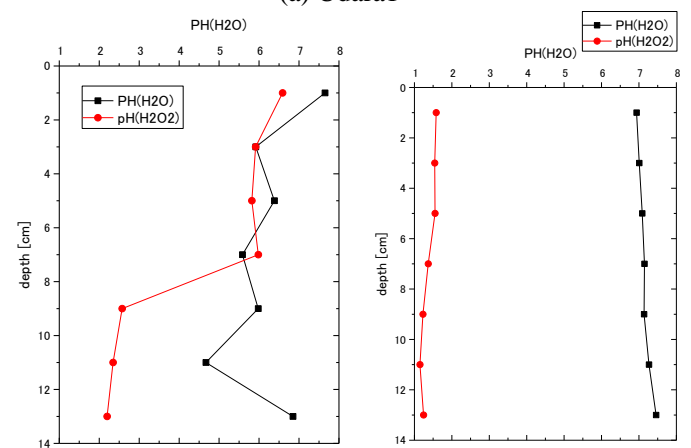

(b) Udara 2
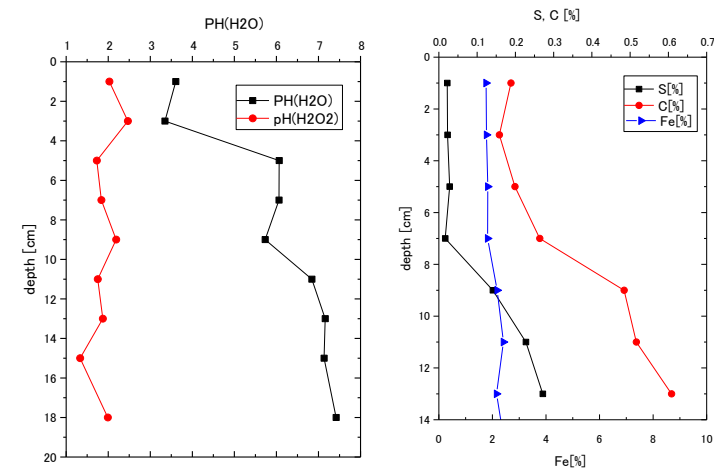

(c) Udara3
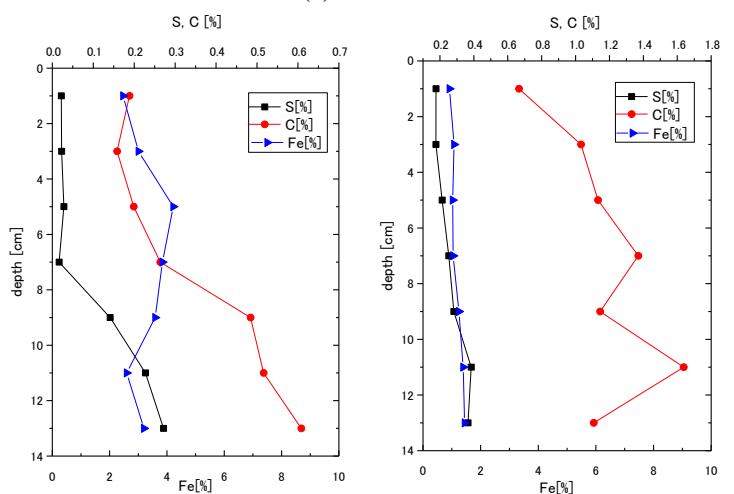

Fig. 4. $\mathrm{pH}\left(\mathrm{H}_{2} \mathrm{O}\right), \mathrm{pH}\left(\mathrm{H}_{2} \mathrm{O}_{2}\right), \mathrm{S}, \mathrm{C}, \mathrm{Fe}$ depth profiles of alluvial soils collected in the Udara River.

The alluvial soils collected at the Udara and Ayanada rivers displayed an identical chemical trend along their entire course. Fig. 4 shows the chemical profiles plotted against depth for the Udara River. In the Udara2 and Udara3 profiles, which were obtained near the river mouth, the iron sulfides were detected near the surface and increased with depth, as evidenced by XRD and analysis of chemical composition. The sulfur and organic carbon content increased in proportion to iron sulfide. In the Udara1 profile, which represented the inland upstream portion of the river with a low water volume, iron sulfide was not detected at the surface but at depths of 7 $\mathrm{cm}$ and below. The distribution profiles of sulfur corresponded to the $\mathrm{pH}\left(\mathrm{H}_{2} \mathrm{O}_{2}\right)$ distribution. The $\mathrm{pH}\left(\mathrm{H}_{2} \mathrm{O}_{2}\right)$ decreased at depths of $7 \mathrm{~cm}$ and below. These profiles also showed a corresponding increase in organic carbon. This trend raised the possibility that the iron sulfides found in the alluvial soils were generated by biomineralization.

In all the core samples, the profiles of iron contents were constant and displayed no dependence on iron sulfide distribution. The iron required for the precipitation of iron sulfide was assumed to be in-situ iron in alluvial soils. (a) Udara 1
S. C [ $[$ ]

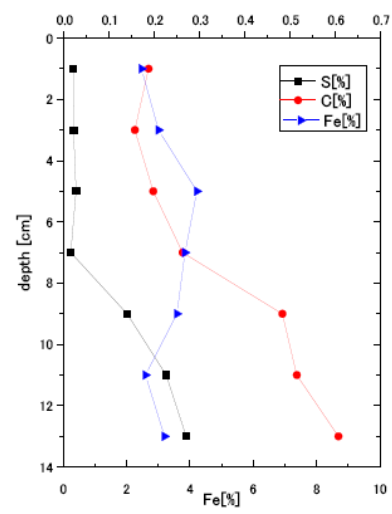

(b) Udara3

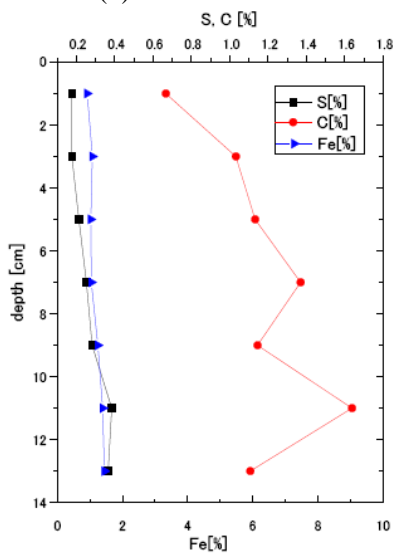

Fig. 5. The depth profiles on $\mathrm{SO}_{4}$ (possibility of oxidation): $\mathrm{SO}_{4} \_\mathrm{p}$ and $\mathrm{SO}_{4}$ (facility of oxidation): $\mathrm{SO}_{4} \mathrm{f}$ of Udara1 and Udara 3 .

The Udara1 and Udara3 profiles of $\mathrm{SO}_{4}$ (possibility of oxidation) and $\mathrm{SO}_{4}$ (facility of oxidation) are shown in Fig. 5. The profiles of $\mathrm{SO}_{4}$ (possibility of oxidation) corresponded to a decrease in $\mathrm{pH}\left(\mathrm{H}_{2} \mathrm{O}_{2}\right) \cdot \mathrm{pH}\left(\mathrm{H}_{2} \mathrm{O}_{2}\right) \leqq 3.5$ and $\mathrm{SO}_{4}$ (possibility of oxidation) $\geqq 400 \mathrm{ppm}$ were the properties of acid sulfate soils [7]. Thus, the alluvial soils containing iron sulfide could be classified as acid sulfate soils. The acidity depended on the iron sulfide content. These soils were abundant at the river mouth from surface to subsurface layer. However, the surficial soils in the inland portion of the river at Udara1 were exposed to air and oxidized by leaching of the sulfite to the river water. These oxidized soils were no longer iron sulfate soils, but they were preserved under the reducing environments in deep layer. It is thus clear that acid sulfate soils are easily altered and their reactivity highly depends on redox environments.

\section{Degradation Ability of Persistent Organic Chemicals by Natural Acid Sulfate Soils}

The typical degradation results were summarized in Table I. The degradation ability clearly corresponded with the iron sulfide content in the different soil types. The red and yellow soils could not degrade dieldrin. About $5 \%$ of the degrading ratio falls within the blank error. On the other hand, alluvial soils identified as acid sulfate soils were able to degrade dieldrin, and the reactivity was high in iron sulfide rich soils. There was no obvious difference in reactivity under sterile and non-sterile conditions. The degradation of dieldrin was assumed to be caused by the chemical reaction with iron sulfide and to be independent of microbial activity. After the reactions, the $\mathrm{pH}$ of each system was weakly acidic to neutral, indicating that the oxidation of the whole soil mass was unnecessary and that the reaction did not require much oxygen. However, the other reactions in this experiment were 
more complicated than the pure mineral reaction. Due to the various organic compounds present in natural alluvial soils, it was not easy to detect the reaction products clearly. The removal of the chloride ion from dieldrin was also difficult to detect due to the effect of seawater on alluvial soils. Thus, the evidence of the reactivity in this experiment was hard to detect except in the case of dieldrin content. There is therefore a need to improve the methods of detection of the reaction products in natural systems.

TABLE I: THE RESULTS OF DEGRADATION EXPERIMENT ON DIELDRIN USING TYPICAL SOILS FROM IRIOMOTE ISLAND

\begin{tabular}{|c|c|c|c|c|c|c|}
\hline location & land soil & land soil & alluvial soil & alluvial soil & alluvial soil & alluvial soil \\
\hline soil type & yellow soil & red soil & acid sulfate soil A & acid sulfate soil B & acid sulfate soil C & acid sulfate soil C \\
\hline sterile/non-sterile & non-sterile & non-sterile & non-sterile & non-sterile & non-sterile & sterile \\
\hline $\mathrm{pH}\left(\mathrm{H}_{2} \mathrm{O}\right)$ & 4.07 & 3.98 & 6.84 & 7.42 & 6.98 & 6.98 \\
\hline $\mathrm{pH}\left(\mathrm{H}_{2} \mathrm{O}_{2}\right)$ & 7.38 & 6.14 & 1.75 & 1.99 & 1.58 & 1.58 \\
\hline contents of iron sulfide & n.d.* & n.d.* & $\bigcirc * *$ & () $* * *$ & (○) $* * *$ & (○)*** \\
\hline $\mathrm{S}[\%]$ & n.d.* & n.d.* & 0.4 & 0.66 & 0.94 & 0.94 \\
\hline $\begin{array}{l}\text { ratio of degradation [\%] } \\
\text { (after } 30 \text { days) }\end{array}$ & 5.6 & 4.9 & 59.6 & 64.8 & 67.1 & 65.3 \\
\hline
\end{tabular}

*n.d.: under detection limits, **○: include iron sulfide, ***(): abundant in iron sulfide.

\section{CONCLUSIONS}

This research was conducted to estimate the natural degradation of persistent organic chemicals in acid sulfate soils. Coastal acid sulfate soils were distributed at the mouths of rivers, and were kept under organic-rich, anaerobic conditions in a subtropical climate. In this location, sulfates were abundantly supplied from seawater and iron is present in in-situ sediments. SRB (sulfate reductive bacteria) were also active and assumed to perform a crucial function in the formation of acid sulfate soils. The soils were stable under anaerobic conditions in the natural system, and they possessed the potential to degrade toxic chlorinated organic chemicals in coastal regions. The degradation ability of acid sulfate soils increased with the iron sulfide content, and caused by chemical reaction of them, not by microbial activity. Although acid sulfate soils are susceptible to exposure to air due to changes in sea level, uplift, and artificial development, and engenders serious environmental problems by the acidification of the soil, they are assumed to play a significant role in the natural attenuation of toxic organic chemicals prevent their proliferation, when kept in the primary anaerobic condition. Unfortunately, coastal acid sulfate soils are limited in their distribution in Japan, but widely distributed in South and Southeast Asia, West and South Africa. The entire transport process of persistent organic compounds is unclear, but coastal acid sulfate soils are assumed to prevent the spread of organic chlorinated contaminants from inland pollution sites to the sea.

\section{ACKNOWLEDGMENT}

We would like to express my gratitude to Dr. K. Miyazaki, Miss M. Watanabe for their technical supports on this research. This research was also financially supported by competitive funds in Research Institute for Geo-resources and Environment, Geological Survey of Japan, AIST.

\section{REFERENCES}

[1] J. Hara, "The effect of oxygen on chemical dechlorination of dieldrin using iron sulphides," Chemosphere, vol. 82, no. 9, pp. 1308-1313, Feb. 2011.

[2] J. Hara, "Chemical degradation of chlorinated organic pollutants for in situ remediation and evaluation of natural attenuation," Organic Pollutants, vol. 14, pp. 345-364, 2012.

[3] K. M. Rosso, U. Becker, and M. F. J. Hochella, "The interaction of pyrite $\{100\}$ surface with $\mathrm{O}_{2}$ and $\mathrm{H}_{2} \mathrm{O}$ : Fundamental oxidation mechanisms," American Mineralogist, vol. 84, pp. 1549-1561, 1999.

[4] T. Kendelewiz, C. S. Dolyle, B. C. Bostick, and G. E. Brown, "Initial oxidation of fractured surface of pyrite $\left(\mathrm{FeS}_{2}(100)\right)$ by molecular oxygen, water vapor, and air," Surface Science, vol. 558, pp. 80-88, Jun. 2004.

[5] C. A. Cohn, S. Mueller, E. Wimmer, N. Leifer, S. Greenbaum, S. R Strongin, and M. A. A. Schoonen, "Pyrite-induced hydroxyl radical formation and its effect on nucleic acids," Geochemical Transactions, vol. 7, no. 3, pp. 1-11, Dec. 2006.

[6] W. Andriesse and M. E. F. V. Mensvoort, "Acid sulfate soils Distribution and extent," Encyclopedia of Soil Science, vol. 1, 2006, p. 1196.

[7] S. Sasaki, "Acid sufate soils from neogene formation I characteristics," Pedologist, vol. 22, no. 1, June 1978.

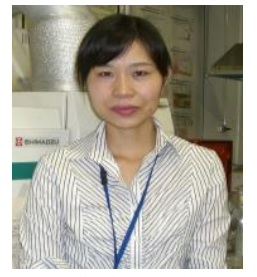

Junko Hara is a senior researcher in Research Institute for Geo-Resources and Environment, Geological Survey of Japan, National Institute of Advanced Industrial Science and Technology, Japan. She got a $\mathrm{PhD}$ in geo-engineering in 2003. Her research background is geochemistry, especially water-rock interaction, and her research area includes soil and groundwater contamination, development of remediation technology by using natural systems, geochemical mapping of subsurface soils, environmental risk assessment, etc. 